\title{
EQUIDAD POLÍTICA, PLURALIDAD CULTURAL Y COMPRENSIÓN DEL PASADO HISTÓRICO
}

\author{
Anibal Fornari \\ CONICET-UCSF
}

La cultura política de una sociedad democrática presupone la pluralidad de procesos de identificación personal y la correlativa diversidad asociativa de sujetos culturales. Éstos están cualificados por experiencias y comprensiones religiosas, filosóficas y morales diversas, dentro de un mismo espacio político-institucional, que ha de objetivar para todos un sentido de la justicia que exprese la convicción y la voluntad de vivir-juntos. ¿Cuál es el problema que, ante esto, debe afrontar una teoría política de la justicia? "Una de las tareas del liberalismo como doctrina política es -dice Rawlscontestar a la siguiente pregunta: cómo debe ser entendida la unidad social, teniendo en cuenta que no puede alcanzarse un acuerdo público en torno a una única idea del bien y que siempre encontraremos una pluralidad de concepciones opuestas e inconmensurables? Y suponiendo que la unidad social sea concebible, ¿bajo qué condiciones resulta posible?"1. Se trata de pensar, a la vez, las unidad política de los ciudadanos y la diversidad social de identidades personales y culturales, las que, en principio, pretenden ser propuestas experimentables, totalizantes y coherentes, es decir, racionalmente responsables. La teoría política, entonces, elabora las condiciones posibilitantes de "la existencia duradera de una sociedad [tendencialmente] justa y estable de ciudadanos libres e iguales que, sin embargo, no dejan de estar profundamente divididos [diferenciados] por doctrinas religiosas, filosóficas y morales razonables" ${ }^{2}$. Rawls, en virtud de una explícita abstracción metodológica, construye teoremáticamente su teoría de la justicia, autoconsciente

\footnotetext{
${ }^{1}$ Rawls, John, "La justicia como equidad: Politica no Metafisica". Agora n 4, Verano (1996), pp. 46-47

${ }^{2}$ Rawls, John, Liberalismo político, México, FCE 1995, trad. Sergio R. Madero Báez, p. 33. (De aquí en adelante, entre corchetes, agregado mio en el texto citado, A.F.)
} 
de su límite respecto a los contenidos identificantes de la pluralidad cultural, pero se halla en dificultades a la hora del tratamiento asuntivo-crítico de los mismos, según la metodología a ellos adecuada. La diversidad cultural es reconocida y, a la par, neutralizada. La cuestión estriba en saber si su interpretación del estado puede ser re-abierta a la dinámica cultural de la sociedad civil, aún desde una profundización de su propio punto de vista formal ${ }^{3}$.

\section{1. "Ideas intuitivas básicas" e identidades culturales plenas}

Desde una concepción política de la persona -como ciudadano-, Rawls establece el fundamento adecuado de un régimen constitucional equitativo y universalmente normativo. El experimento político-reflexivo de implicarse en la "posición original" requerida a todos en cuanto pretenden convivir como ciudadanos, coloca bajo un "velo de ignorancia" precautorio a la propia identidad e historia cultural, así como a la posición lograda y a la que le corresponda desempeñar ulteriormente. Es un medio de autoesclarecimiento público para reconocer la racionalidad y consecuente universalidad de los principios de justicia, como criterios de funcionamiento asociativo entre personas libres e iguales. Al prescindir de todo compromiso con una visión moral, filosófica y religiosa omnicomprensiva, se establecen los principios y las derivaciones de esta concepción equitativa de los ciudadanos, sin que eso sea un ideal ético que pretenda gobernar la totalidad de la vida, sino "un ideal integrado a una concepción política de la justicia que se aplica a la estructura básica de la sociedad" ${ }^{4}$. Ahora bien, esas "visiones omnicomprensivas" del bien, ¿tienen en Rawls una signifi-

\footnotetext{
${ }^{3}$ Sobre eventual incompatibilidad interna entre el primero (Teoria de la Justicia) y segundo (Liberalismo politico) Rawls, respecto a la fundamentación "filosófica" de la democracia y el liberalismo, Cfr. Rosenkrantz, Carlos, "El nuevo Ranils", Revista Latinoamericana de Filosofía, Vol. XXII, n², Primavera (1996). pp. 223-249. Sobre validez normativa y posibilidad de conciliación entre libertad e igualdad, Cfr. Hernández López, Daniel, "John Rawls: de la Teoría de la Justicia al Liberalismo Político", Revista de Filosofía, n²8 (1998-1) , pp. 75-97

+ Rawls, John, "La justicia como equidad ...". p. 43
} 
cación constitutiva para formar la estructura básicamente justa de un estado democrático estable?

En primer lugar, la "cultura pública" de una democracia constitucional debe contener "ideas intuitivas básicas", extraídas de las experiencias y doctrinas omnicomprensivas inherentes a la historia de esa sociedad, convergentes en un "consenso superpuesto". El núcleo de éste debe ser identificado por la teoría política de la justicia, como "ideas intuitivas compartidas", como valores entresacados y establecidos más allá de sus diferentes fundamentos vivos, en cada caso reconocidos. Así los valores quedan metodológicamente aislados de la raíz ontológico-existencial nutriente. Pero este corte de Rawls no implica que esas intuiciones axiológicas básicas compartidas deban ser parasitariamente adoptadas, como si el consenso superpuesto fuese un modus vivendi que va de suyo. Un mero acatamiento fáctico, correlativo a un escepticismo relativista acerca del estatuto ontológico de las concepciones omnicomprensivas, sería democráticamente equívoco y preparatorio de una homologación cultural totalitaria. Establecer la coherencia jurídica y la moralidad básica, constitucionalmente normativas, exige una restricción de esas intuiciones en función de una concepción política universalizable y constituyente de ciudadanías válidas. Pero la misma concepción de la justicia como equidad es también ya una concepción moral que integra otras concepciones compatibles con ella, acerca de la persona, de la sociedad, del derecho, de la justicia. Sobre todo, para poder materializarse, debe valorar e integrar virtudes vividas y cada vez retransmitidas (confianza, honestidad, respeto, solidaridad, etc.), cual disposiciones cooperativas. Éstas, para ser efectivas, deben estar integradas en una perspectiva totalizante y fundada del sentido de la vida. De lo contrario tienen una permanencia voluntarista históricamente fugaz y una aplicabilidad circunstancial ligada a las variaciones del sentimiento y de las pasiones, pues carecen de una estructuración existencial coherente y razonable. Con la gravedad de que, sin esas disposiciones estables, los principios de justicia política quedan en el aire o son acatados 
apenas en mezquina y temerosa prevención de una posible e irrecuperable desventaja.

En segundo lugar, estas concepciones teleológicas del bien, en principio compatibles, existentes en la base social, forman un plexo de "fundamentaciones adicionales" ${ }^{15}$ respecto a las ideas intuitivas convergentes en el consenso superpuesto. Este carácter adicional se sustenta como "complemento" requerido, en el marco operatorio del proceso abstracto-reflexivo, para construir los principios formales esenciales de la justicia como equidad política. Porque esas ideas intuitivas y las concepciones englobantes del bien que las sustentan en el plano racional ontológico, son en realidad prioritarias para la efectivización histórica del estado constitucional equitativo. Por eso, ellas deben reactualizarse críticamente para no decaer en un proceso degenerativo de descomposición fragmentaria e irracional. Los "teoremas" propios de la teoría política de la justicia, organizadores de la unidad institucional de la sociedad, deben ser nuevamente reconocidos y reapropiados por las personas reales que participan sucesiva y problemáticamente de experiencias culturales omnicomprensivas. Pues son éstas las que posibilitaron históricamente a esos mismos principios de equidad, generando el consenso superpuesto y preparando la razonabilidad operatoria del teorema político-moral.

De lo precedente, emergen estas preguntas: $¿$ basta la formal institucionalización homologatoria de las intuiciones básicas compartidas, para que éstas no queden en un mero modus vivendi acomodaticio, que acaba convirtiendo al estado mismo en el bientelos último, pero ahora coercitivo de la sociedad toda, ideológicamente absorbida por la "síntesis política de la verdad y del bien"

\footnotetext{
${ }^{5}$ Rawls J., ibidem, p. 45

${ }^{6}$ Cfr. Ricoeur, Paul, Histoire et Vérité. Paris, Seuil 1964, pp. 165-197. El A. reflexiona sobre la exigencia ideal de unidad de la verdad, a través de la diferenciación de sus niveles de manifestación, al par que cuestiona la pretensión de precipitar la "sintesis especulativa" (se diría "racionalista"), la "sintesis política" (se diria "ideológico-totalitaria") y la "sintesis clerical" (se diría "doctrinaristaformal"), en cuanto totalizaciones abstractas ejercidas sobre el ideal de lo verdadero, antropológica-
} 
¿Acaso, las concepciones omnienglobantes del bien, que posibilitaron el consenso superpuesto, son reducibles a meras "circunstancias

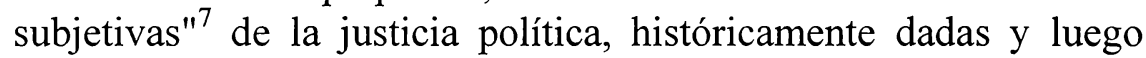
descartables en los tiempos maduros del sujeto político autónomo y teoremáticamente motivado? Las metódicamente suspendidas concepciones teleológicas, ¿subsisten indefinidamente de suyo si no son re-experimentadas y racionalmente explicitadas?, ¿O deben ser definitivamente reducidas a depósito ideológico disponible para reactivar, circunstancialmente, las intuiciones básicas en función de la gobernabilidad de la sociedad? ¿Requieren ellas del ejercicio público de la racionalidad, como reiterado inicio del preguntar fundamental y como problematización apropiativa de contenidos sustantivos, configuradores de la significatividad del espacio público y del ejercicio pleno de la razón, reconocida en sus diversos niveles metódicos? Un auténtico estado de derecho, ¿no debería garantizar el dinamismo público, pre- y meta-estatal de la razón y de la acción, para que las personas y los movimientos comunitarios confronten y desarrollen críticamente su identidad, enriqueciendo de paso el consenso superpuesto y posibilitando disensos fundados, comunicables y convivibles?

La respuesta a estas preguntas constituye un requisito para el dinamismo estable y para el desarrollo básicamente justo de una democracia viva. Rawls descarta que hoy sea viable establecer politicamente una concepción teleológica única del bien, instituida normativamente para todos. Esto, indudablemente, debe ser reconocido y confirmado a un nivel aún más profundo. Porque es esencial para la vida política en sí misma, y en cuanto democrática, y no sólo para el hoy. Pero esto presupone, también políticamente, plena libertad cultural y educativa públicas, como equidad estatal que no penaliza económica y culturalmente a la sociedad cuando ésta ejerce su derecho de educar, proponiéndose en el espacio público. La

mente constitutivo como camino reflexivo desde la experiencia, antes que como poder y como discurso.

${ }^{7}$ Rawls J., "La justicia como equidad...", p. 46 
equidad no se confunde con la hegemonía del estado-télos, expropiado a la sociedad en su conjunto por un determinado sujeto cultural que presume expresar la "neutralidad". El carácter instrumental del estado democrático, como órganon de unidad social y de equidad político-institucional, remueve los obstáculos y valoriza las presencias culturales actuantes en la praxis social, cuya pluralidad, si es consistente, promueve la cualidad del bien común.

\section{Epistemología de la unidad política y ontología de la plurali- dad cultural.}

El corte epistemológico de la teoría política de la justicia responde a la acendrada determinación rawlsiana por organizar una unidad estatal equidistante de la sociedad. Otorga así una primacía no dialéctica al estado respecto a la posible demanda de identidad de los integrantes de la sociedad civil, en el horizonte de la verdad y del bien. "El concepto de justicia es independiente de, y previo a, el concepto del bien en el sentido de que sus principios limitan las concepciones del bien que son permisibles. Una estructura básica justa y sus instituciones fundamentales establecen el marco dentro del cual pueden promoverse las concepciones del bien. En otro lugar -dice Rawls-, denominé a esta relación entre la concepción de la justicia y las concepciones del bien la prioridad del derecho"8. Esta prioridad de la estructura política sobre las exigencias más constitutivas de la persona, de la sociedad civil y de la misma filosofía en su dinámica completa, es hecha a favor de éstas. Pero ahí está latente una alteración del sentido y alcance de la razón con validez pública, que puede terminar en lo contrario de lo previsto. El estado y sus variadas instituciones es, obviamente, gobernado por hombres concretos, dotados de pertenencia, de convicciones ideales, y también de pasiones que pueden destruir el sentido del poder. Si la prioridad del marco institucional y de la neutralidad equitativa no están acompañadas de una capacidad de valorización

\footnotetext{
${ }^{8}$ Rawls J. , ibidem, p. 47 (cursivas mías, A. F.)
} 
de las concepciones del bien, tenderá a ser conservada por sí misma como lugar de concentración de poder, dictaminando lo que es lícito hablar y lo que se debe acallar en el ámbito de la discusión pública. Así el poder mismo se convierte en fin y quienes lo ejercen tienden a esconder o denegar su pertenencia cultural para poder neutralizar a las demás. El criterio político acerca de las concepciones del bien permisibles o excluibles, no está explícitamente abierto a criterios meta-políticos más profundos de racionalidad, con los que dialectizarse. Entonces, la sombra de la "razón de estado" recubre con su discrecionalidad a la "razón pública". Al par que se delimita el alcance del espacio y de la razón públicos, se ensancha la atribución política de discriminar lo culturalmente pertinente a un estado democrático.

Ciertamente, la teoría política de la justicia, en cuanto tal, no pretende homologar las experiencias culturales ni la búsqueda de verdadera identidad y comunidad. Ella se propone forjar mediante un método parcial de esclarecimiento reflexivo y de accesible comprensión- un marco jurídico equitativo universalizable que facilite la promoción de todos y el plural "agonismo"' 9 -antes que un apriorístico antagonismo- de los sujetos constituyentes de la sociedad civil. Ese marco de equidad ciudadana garantiza a todas las concepciones del bien estar presente en forma personal y asociativa, para vivir y proponer a todos la razonabilidad y el testimonio de su respuesta al problema humano. Se exponen así a la verificación de su concepción del bien, tanto hacia adentro como hacia afuera de la propia dinámica comunitaria. Pretender imponer

\footnotetext{
${ }^{9}$ Cfr. Mouffe, Chantal, "Pluralismo agonista: la teoria ante la política. Entrevista con Ch.M.", (realizada por Antonella Attili), Revista Internacional de Filosofia Política, no 8, 1996, pp. 139-150. Este agonismo, que pretende sustraer la dialéctica originaria de lo político de la relación amigoenemigo y situarla en el plano más civilizado de la relación entre iguales en posiciones adversarias razonables, sin embargo, es realmente tal cuando se ubica en un nivel antropológico pre- y metapolítico, como tarea de confrontación, al par íntima y alterativa, en pro de una identificación exigente. Una identidad asumida en forma autoconsciente y posibilitada desde un encuentro eminente con otro, en el que se vislumbra un camino de identificación que abarca la totalidad de la vida y no sólo el aspecto político, es realizada en el horizonte del reconocimiento de la dignidad fundamental y universal de lo humano, y también "frente al mundo" y su mentalidad dominante, partiendo desde la herencia cultural de la propia comunidad de pertenencia.
} 
afuera de la propia dinámica comunitaria. Pretender imponer políticamente a todos desde el estado, una identificación cultural unívoca, es atribuirse despóticamente una representación exhaustiva de las presencias sociales reales. Una verdadera identidad nunca pasa por encima de las personas concretas, siempre emergentes a la vida y al problema del sentido. Ellas se ven impulsadas a reiniciar, desde su libertad respondiente y desde su educación en el uso integral y abierto de la razón, su propio camino de identificación, así como a re-encontrar su pertenencia comunitaria profunda. La identificación existencialmente persuasiva porque racionalmente totalizante de todos los factores de la experiencia humana, queda a mitad camino si se reduce a la sistematización ideológica de algunos valores selectivamente extraídos del plexo histórico-cultural integral, sin percibir sus nexos lógicos con la totalidad de la cuestión del sentido y sus implicaciones existenciales últimas en relación a los problemas efectivos de la vida. La extracción axiológica desarraigada del humus ontológico de la experiencia antropológica e histórica puede, incluso, ser coherente, pero queda fijada en la exaltación unilateral de algun aspecto de la experiencia humana (p.e. el político). De ahí la necesidad "emotivista" de recargar la coherencia del ideario con la postulación del "apasionamiento", tal como en parte lo evidencia Chantal Mouffe ${ }^{10}$. Su reivindicación de una identidad resuelta por "desneutralización", se pliega a un tipo de agonismo que es ideológico en tanto está centrado en el nivel secundario del discurso, de las estrategias retóricas y del trabajo sobre el sentimiento.

Los presupuestos de Rawls dificultan la comprensión del proceso antropológico de identificación. Su kantiano rechazo de la aristotélica concepción teleológica de la vida política contiene, sin

\footnotetext{
${ }^{11}$ Cf. Mouffe Ch., o. c., p. 150: Frente al repliegue liberal en la neutralidad de lo público, se propone revitalizar la ideología liberal como cuestión de "movilizar las pasiones, no de afirmar que somos neutrales, sino movilizar las pasiones hacia los valores liberales. Pero es una cuestión de redescripción, de persuasión, de retórica y no de empezar a hacer tratados para mostrar que eso (el neutralismo) es el verdadero sentido del pluralismo".
} 
embargo, una ambigüedad que da pie a la superación de su propio límite. En efecto, del "consenso superpuesto" son selectivamente extraídas ideas intuitivas compartidas, informadoras del sentido de las diversas prácticas e intercambios sociales cotidianos. Estas ideas son concentradas en los axiomas básicos de la teoría política de la justicia. Pero no por eso dejan de implicar, en los estados históricos, un vigente sistema de convicciones acerca del bien, de los valores y del sentido del mismo convivir político. De la concepción omnienglobante del bien recibe el estado la calidad ética de los ciudadanos, gracias a la cual el destino de la ciudad también íntimamente les concierne y los lleva a comprometerse con las exigencias políticas de la justicia. El propósito de Rawls es evitar que la dinámica del poder político se apropie del bien y haga acepción de personas. Los ciudadanos libres e iguales serían afectados en su dignidad si fuesen coaccionados a permanecer mecánicamente en una identidad última políticamente establecida y judicialmente asegurada. Quedarían desamparados y excluidos de la vida política si no permaneciesen en ese mecanicismo cultural, habida cuenta del imprevisible ritmo personal de las decisiones y de la decantación existencial y racional de las convicciones últimas. Por eso, el concepto de ciudadanía es necesario y alude a un valor ético-político universal, puesto en evidencia desde aquél civis romanus sum, appelo Caesarem, de Saulo de Tarso ${ }^{11}$, exigido al estado ante la condena infligida por parte de los supuestos custodios de su cultura de pertenencia y de su originaria comunidad histórica.

Como "personas libres, los ciudadanos exigen el derecho de que su persona sea considerada independiente de toda concepción particular del bien y de su esquema de fines últimos; exigen no ser identificados con ellas [en cuanto ciudadanos]. Dada su capacidad moral para elaborar, revisar y perseguir racionalmente una concepción del bien, los cambios no afectan su identidad pública como personas libres. Por ejemplo, cuando los ciudadanos se convierten

"Cfr. Badiou, Alain, Saint Paul. La fondation de l'universalisme, Paris, PUF 1997 
de religión o, simplemente, abandonan la fe, no dejan de ser, por cuestiones de justicia política, las mismas personas que eran antes"12. Esta necesaria dimensión ética universal inherente a la categoría política del hombre en cuanto ciudadano, significa, si se ha de ser coherente, que el télos del bien común político está en función de un arkhé y de un télos pre- y meta-político, que cualifica la trascendencia públicamente válida de la persona concreta, en cualquier instancia y forma de su existencia, por el hecho mismo de existir. $\mathrm{Su}$ dignidad ontológica y pública excede todo horizonte de pertenencia comunitaria, toda cualificación resultante del oficio que realiza o incluso de la (in)moralidad de sus acciones, y debe ser reconocida en toda situación de estado. La persona humana en sí misma es el universal concreto que funda el universal formal de la ciudadanía, y no a la inversa. La comunidad de pertenencia que sostiene este ethos personal está constituida por una autoconciencia ecuménica ${ }^{13}$, portadora del sentido del universal concreto. La trascendentalidad del ciudadano, fundada en su capacidad moral para elaborar, revisar y perseguir racionalmente una concepción del bien, no sería reconocida en forma coherente si estas capacidades se remitiesen a la equívoca categoría de razón privada. La razón sin más es siempre personal y, al par, es apertura intencional a la totalidad y mediación intersubjetiva públicamente referida. Toda relación interpersonal significativa y comprometida se realiza en el horizonte de la vida pública.

De lo dicho se deduce también la ilegitimidad de una concepción política que presuponga en todos los ciudadanos el consentimiento a una sola concepción del bien institucionalmente normativa, aún en las sociedades culturalmente homogéneas. Porque ese "todos" está afectado por múltiples contingencias al respecto, lo

\footnotetext{
${ }^{12}$ Rawls J., "Justicia como equidad...", p. 40 (primeras cursivas, mías, A. F.)

${ }^{13}$ Este concepto indica la trascendencia de las personas respecto a cualquier totalidad que las pretenda exhaustivamente abarcar, y al mismo tiempo, refiere a una experiencia metapolítica y transcultural de la libertad, que posibilita discernir y asumir todo indicio de positividad y de valor dentro de cualquier experiencia y contexto.
} 
que es propio de sujetos finitos insertos en el intercambio de las generaciones y en procesos personales diversos y polémicos de maduración, en su paso por el escenario social. El asentimiento pleno a una concepción consistente del bien es tanto un logro esforzado de la razón, leal a la estructura del deseo de quien la ejerce, cuanto el gratuito acontecimiento de un encuentro histórico y personal. Es, entonces, políticamente decisivo reconocer el espacio público orgánico de libertad para este ejercicio sistemático de la racionalidad y de la verificación, referido a la identidad constitutiva de las comunidades de pertenencia cultural configuradoras de la sociedad civil. Pero de ahí a decir que "el liberalismo es una concepción política que supone la existencia de múltiples concepciones del bien, conflictivas e inconmensurables, cada cual compatible con la plena racionalidad de los seres humanos"14 ${ }^{14}$, es diluir el plexo histórico-cultural de la sociedad civil y el sentido personalpúblico de la razón, obstruyendo la posibilidad del mutuo reconocimiento a partir de criterios básicos de inteligibilidad ${ }^{15}$. Si éstos no son reconocidos, la "cultura pública de una sociedad democráti$\mathrm{ca}^{16}$ se reduce a relaciones y diálogos meramente instrumentales.

\section{Reconocimiento mutuo y "tolerancia virtuosa"}

Para Rawls, "la estabilidad de esta unidad [en una sociedad democrática centrada en la equidad y motivada a la cooperación social] depende fundamentalmente del contenido de las doctrinas filosóficas, religiosas y morales disponibles que convergen en el consenso superpuesto. (...) Este consenso superpuesto parece mu-

\footnotetext{
${ }^{14}$ Rawls J., ibidem, p. 46 (cursivas mías, A. F.)

${ }^{15}$ La cuestión del pluralismo cultural debería ser pensada en sus proporciones inteligibles. No cualquier postura es una cultura; tal vez sea un "proyecto" con fuerte componente circunstancial y sentimental. Incluso una gran tradición troncal facilita y admite libres desprendimientos fragmentarios que son in-inteligibles sin ella. Pero lo propio de los fragmentos obtenidos por oposición es clausurarse en su unilateralidad y tornarse incomunicables entre sí. Sólo lo logran al re-comprenderse autocríticamente desde el tronco vital. Es de alto valor crítico, al respecto, el abordaje ético-histórico de Alasdair MacIntyre en: Whose justice? Which rationality?, New York 1988, y Three Rival Versions of Moral Inquiry (Encyclopaedia, Genealogy and Tradition), Indiana 1990.

${ }^{16}$ Rawls J., "Justicia como equidad ...", p. 47
} 
cho más estable que un consenso que se base en perspectivas que expresan escepticismo e indiferencia hacia los valores filosóficos, religiosos y morales, o que considere a la aceptación de los principios de justicia como un simple y prudente modus vivendi dado el equilibrio existente de fuerzas sociales"17. La importancia de la concepción de la justicia como equidad radica en que, si ella es bien entendida, posibilita el desarrollo de la autoconciencia de las experiencias y conceptualizaciones del bien más comprensivas, actuantes en la sociedad. Éstas aportan, en tanto son lo que deben $\operatorname{ser}^{18}$, una estabilidad viviente a los valores ciudadanos y una conciencia de la función propia y del límite crítico de la vida política. Sustentan la apertura de las personas y de la sociedad civil en una conciencia teleológica que nutre a la vida política, porque la precede, la asume y la supera. Pero para Rawls esta perspectiva forma parte de un "razonamiento (que) es altamente especulativo y señala cuestiones que son poco entendidas"19. ¿Dónde radica esa ininteligencia? Para Rawls, la compatibilidad "política" entre esta perspectiva ontológico-teleológica y su perspectiva jurídico-formal de la justicia como equidad "no tiene respuesta práctica"20, porque la segunda excluye a la primera, tal como la democracia excluye al autoritarismo ${ }^{21}$. Exacerba así la incompatibilidad entre lo que él llama la concepción de la justicia -que tiene un valor teórico y práctico formal universal-, y las concepciones del bien -que tienen un valor hermenéutico de contenido relativo-, a las que el principio

\footnotetext{
${ }^{17}$ Rawls J., ibidem, p. 47

${ }^{18}$ Una concepción omnienglobante del bien comporta, entre otros, estos aspectos formales: tener el valor de la prueba, como propuesta cultural positivamente generativa de una historia y de un flujo de civilización, autoconsciente de la diferencia esencial entre lo humano y lo prehumano; expresar el valor de la razón a través de su sistematicidad abarcadora de la realidad en su conjunto, abierta de algún modo a la trascendencia del signficado último; expresar el valor de la libertad como condición básica de una sociabilidad centrada en la responsabilidad de educarse para convivir y procrear; disponer del valor autocrítico de la justicia como conciencia sistemática de la diferencia entre el bien y el mal, y el sentido de la alteridad y de los límites.

${ }_{19}^{19}$ Rawls J., ibidem, p. 48

${ }^{20}$ Rawls J., ibidem, p. 46

${ }^{21}$ Esta reducción pan-política del problema racional de la identidad personal y cultural, debería reestablecer la pregunta acerca de cual de las dos "perspectivas" (teleológica y formal) es más abierta y efectivamente integradora de la verdad de la otra.
} 
de tolerancia coloca en pacífica y extrínseca coexistencia. Los significados antropológicos no pueden ser afirmados sino como opiniones más o menos bien fundadas. Sin embargo, los significados empeñados en un proceso de identificación exigente no se resignan al nivel de la opinión sino que resultan de un agonismo racional de índole alterativa, de una confrontación experiencial y racional, interna y externa a la persona y a su comunidad de pertenencia, según un criterio ontológico de verdad. La misma dimensión histórica está entre esos tópicos alterativos, que impiden la postración del yo en una seudo-identidad monádica, unidimensional y autoconformada.

El principio de tolerancia reivindicado por Rawls -desde una gnoseología blanda y relativista, correlativa a una epistemología dura y sistémica- tiene como parámetro de discernimiento de los significados antropológicos y culturales, su funcionalidad con respecto al concepto de democracia. Los contenidos son significativos por su utilidad política. El estado equitativo, en efecto, no oficializa en forma excluyente a concepciones omnienglobantes del bien, aunque ellas hayan generado la institucionalización de un tal estado desde la sociedad civil. Esto no significa cultivar la indiferencia o la distancia política artificiosa respecto a la realidad cultural que produjo, sostiene y asume ese orden constitucional, como si se tratase de un sistema jurídico que no incluye la indicación de sus fundamentos antropológicos y morales originantes. Significa, más bien, que los procesos de identificación exigente deben ante todo correr libremente sus riesgos en el ámbito de la sociedad civil que tal estado debe proteger como espacio público orgánico de configuración antropológica totalizante. Entonces, el nivel políticoinstitucional de la justicia como equidad no debe ser confundido con el nivel cultural-educativo público (no estatizado) de la verdad o de la pretensión de verdad, dirigida propositivamente a la posible receptividad y libertad educativa de todos. 
El estado de derecho implica una ascesis metodológica en cuanto no se arroga el papel de juez de la verdad de los dinamismos omnienglobantes de identificación que, sin embargo, configuran el consenso superpuesto que lo sustenta. Un estado educido desde la sociedad y no impuesto a ella, conlleva en su impronta constitucional ese reconocimiento, incluso para dar cuenta de su propia legitimidad y para permanecer como realidad política válida. En la medida en que se constituye para que la sociedad crezca en posibilidad de iniciativa y en capacidad de juicio sobre las propuestas más correspondientes a las exigencias propiamente humanas de sus miembros, también renuncia a ser un estado confesional y pedagógico (religioso, agnóstico o irreligioso). La auténtica "laicidad" del estado renuncia en su ascesis metodológica a apropiarse de atributos que exceden su competencia, en todas sus instituciones. Sobre todo debe renunciar a ese confesionalismo educativo encubierto bajo el manto de la "neutralidad", que se vale del estado para imponer como verdad de la razón pública al "laicismo". Éste, al censurar como impertinentes o ingenuas a las preguntas que expresan y guían a la razón ante la inevitable demanda existencial de identificación totalizante, consagra a la ideología cientificista y a sus sucedáneos, entre ellos la fetichización del poder y del éxito, como representantes de la objetividad y de la universalidad.

La tolerancia como equidad positiva y activa consiste en reconocer políticamente la existencia de diferencias consistentes, en tanto ámbitos de referencia para procesos de identificación personal exigente. Según la primera formulación del principio de justicia de Rawls, esto significa reconocer la igualdad ante la ley de las concepciones omnienglobantes del bien. Junto al incondicional derecho a la vida, todo individuo tiene igual derecho a la libertad de conciencia, de expresión, de asociación, de educación y de iniciativa para responder a sus exigencias humanas, sin que sus preguntas fundamentales sean recluidas en una obtusa privacidad. Una concepción política de la justicia como equidad coloca "entre paréntesis la cuestión de la verdad, no por escepticismo -advierte Ricoeur-, 
como en una concepción que partiría del relativismo, sino porque la cuestión no es pertinente en este plano (...). Ante la ley los individuos son considerados como portadores de creencias, convicciones e intereses que definen el contenido de sus discursos" ${ }^{22}$. Atendiendo ahora a la segunda formulación del principio de justicia, se prepara la transición del plano institucional al plano propiamente cultural y moral del reconocimiento mutuo. El procedimiento consiste en aumentar las ventajas de los más desfavorecidos en el reparto desigual de beneficios y cargas, tratando de disminuir también las desventajas que ya deben acatar los más favorecidos. Pero siempre se trata de individuos portadores de exigencias humanas y de convicciones correspondientes. Proteger la libertad cultural y los intereses de los más débiles, no significa constituirlos en clientela incapaz y cautiva de un estado presuntamente neutro, sino de reconocerlos como posibles protagonistas de una historia cultural y social manifestativa de su personalidad y enriquecedora del bien común.

La tolerancia inherente al principio de equidad estatal, en base a un prejuicio filosófico-político que atribuye al estado el papel de última instancia de síntesis social, se desvía de su cometido valorizador de las diferencias consistentes. Al menos tres figuras devaluativas de la exigencia humana de identificación son, en realidad, sobreposiciones de la voluntad de poder y de su miedo a la libertad, entendida como demanda personal profunda e indomable de adhesión a la alteridad del significado, en cuanto éste es el bien correspondiente al deseo-de-ser. Ciertos enmascaramientos en la tolerancia hacen uso de confusiones conceptuales previas que irrespetan la dignidad personal y, por eso, son figuras de lo intolerable. Se da la figura de lo intolerable institucional cuando, confundida la dinámica política hacia la justicia con la dinámica cultural y educativa hacia el descubrimiento y la verificación de la verdad, se intenta subsanar la tendencia al despotismo que tal confusión implica, instaurando la neutralización educativa de la exigencia de verdad

\footnotetext{
${ }^{22}$ Ricoeur, Paul, Lectures I. Autour du politique, Paris, Seuil 1991, p. 300
} 
en aras de la exigencia política de equidad. No es difícil este deslizamiento, porque el espacio público implica reglas de uso por parte de las presencias que convergen en él. "Ahora bien, el punto delicado es distinguir las reglas de orden que aseguran la libertad de expresión, de las reglas que restringen el contenido de los discursos. Las reglas de orden no tienen de por sí otro objetivo que acrecentar los beneficios de la libertad. (...) Estamos en el peligroso cruce entre la tendencia a la obstrucción entre esferas rivales de libertad y la tendencia 'ideológica' de la institución pública en confundir las reglas de orden con las reglas dirigidas contra el contenido de ciertos discursos. En este sentido, lo intolerable es siempre de temer. El estado absolutamente neutro es una idea límite que sirve para medir la distancia entre lo real y lo ideal. Pero, ¿por qué el estado absolutamente neutro es algo que no existe? Pues, porque él nunca nace en el vacío, sino que se vincula a una cultura que a la vez él expresa y protege" ${ }^{\prime 23}$. Cabe abrir la pregunta: ¿es la neutralidad un ideal?

La segunda figura, lo intolerable ideológico, tiene dos puntas. Por un lado, la instrumentación política de cierta subjetividad de la sociedad concurrente con la formación de las instituciones de un estado y con el poder gobernante que las actualiza, de manera que éste puede autointerpretarse como representación cultural exhaustiva de la sociedad. Así, toda otra expresión de la subjetividad de la sociedad, para presentarse públicamente debe subordinarse a esa postulada representatividad general. Por otro lado, la instrumentación del neutralismo como fachada para legitimar una hegemonía, pues quien es representante de la "neutralidad" cultural expresa la "objetividad", procede con "imparcialidad" y se atribuye la "superioridad" sobre las partes o perspectivas culturales particulares, tenidas por sub-racionales. A menudo esa presunta imparcialidad es vocero ideológico del positivismo, que en sus variables entroniza al discurso de las ciencias como tópico último de verdad

${ }^{23}$ Ricoeur P., Ibid. pp. 301-302 
válida para la toma de decisiones fundadas sobre los asuntos humanos. Pero, sobre todo, ese neutralismo expresa la abdicación burocrática de la capacidad de juicio prudencial del gobernante, en cuanto a valorizar los sujetos culturales constituyentes de la energía constructiva propia de la sociedad civil. Esto implica una ininteligencia política de la sociedad y la global mediatización totalitaria de tales sujetos por parte de los funcionarios y de los sistemas institucionales del estado. Es decir: una paralizante estatización de la sociedad, cuyo inicio radical está en lo menos visto y en lo más decisivo, en la cultura y en la educación y, por supuesto, en la forma de subsidiarlas. Reducir el sentido político de la justicia como equidad, a la neutralidad, conduce a censurar la libre profundización histórica y reflexiva de las propuestas culturales, y a reproducir la superficialidad (des)educativa. Por eso se subraya aquí el sentido de la equidad política positiva, la única plenamente compatible con una democracia viva.

El sentido de la tolerancia real se esclarece en el concepto de consenso conflictual, que la transforma en tolerancia dificil o virtuosa ${ }^{24}$. No se trata sólo del reconocimiento del otro en su derecho a existir en la diferencia, sino de mucho más. De procurar con el otro una "convivialidad" cultural, porque también él es, por principio, no un antagonista de la identidad de uno mismo, sino un agonista que vive, de modo análogo e irrepetible, nuestra propia búsqueda y lucha por una identidad personal y comunitaria, auténtica y verdadera. Pero a la búqueda del otro no se puede acceder desde una distancia objetivista, sino dando espacio al encuentro con él y a la posible revelación de su experiencia, de sus convicciones y del sentido de su búsqueda. Lo que es viable en la medida en que uno mismo se reconoce investido por esas exigencias trascendentales de las que también el otro es humano portador, convocado en el diálogo a hacerse cargo de las mismas. En la medida que uno mismo no esté instalado a priori en la indecisión programada, recibe

\footnotetext{
${ }^{2+}$ Cfr. Ricoeur P., ibidem, p. 304
} 
ya al otro como imprevisible momento alterativo de una posible revelación de lo que significa llegar a ser uno mismo como ipse. Entonces, el auténtico consenso conflictual no resulta apenas del polemizar argumentativo entre convicciones rivales estancas, sino del encuentro humano que hace aflorar la pregunta del otro dirigida a uno mismo. Tal como nuestras verdaderas preguntas están en el origen de nuestras auténticas conviciones.

\section{Comprensión del pasado histórico e identidad personal exi- gente}

Las verdaderas preguntas suponen un deseo racional de significado y de "convivio" cultural que, si es realizado en el espacio público social de la libertad educativa (no polarizado por la lucha por el poder estatal como botín para la representación general), no precisa colocarse en una postura polémica defensiva sino que necesita profundizarse dentro de una lógica de amistad social. ¿Qué es lo que permite tomar con seriedad las propias convicciones y las del otro? Es la anticipación de la autenticidad, momento positivo previo que informa a la tolerancia virtuosa, en el sentido de que nuestras (de unos y otros) certezas existenciales, nuestras cuestiones de confianza y nuestras trabajadas convicciones, son el fruto de una adhesión razonable y libre. Reconocer esto en uno mismo y en el otro indica que nos situamos en el respeto y nos concebimos desde la categoría de persona y no de cosa. Esto fundamenta y traduce en la sociedad civil los principios de justicia establecidos en el plano abstracto institucional. Así las convicciones personales y comunitarias reciben una benéfica transformación: no pueden retraerse mecánicamente en la costumbre ni parcializarse en lo ideológico, donde se endurecen las rivalidades eventuales. Ellas se problematizan, entran en diálogo ante todo con la experiencia viva del dinamismo integral del sujeto encarnado y así recuperan la autoconciencia de la propia pertenencia histórica profunda. 
Sin confrontación con la hipótesis de sentido transmitida desde el pasado histórico, no hay proceso de identificación exigente ni diálogo sustancial entre sujetos culturales. La identidad queda librada a la puntualidad reactiva ante la circunstancia, carente del sentido de lo que se vive; o tambien a la proyección idealista de un mero parecer y a la exaltación míope de lo unilateral, lo que falsifica la problematización y fanatiza la eventual rivalidad. En el plano mismo donde debe formarse el auténtico sentido del respeto, emerge también uan tercera figura: la de lo intolerable cultural. "Es lo que no merece respeto, porque está fundado, precisamente, sobre el irrespeto, esto es, sobre el rechazo a presentir la libre adhesión en la convicción rival"25. La irrespetuosa presunción de irracionalidad, o de mera opinión o de obtusa creencia en las convicciones centrales del otro, incentivada por el carácter emotivista o axiológico-parcial de las propias en cuanto entresacadas de una historicidad cuyos rastros se ha perdido, desata un estilo de criticidad negativa que intenta vanamente construir una identidad original desde una autonomía que parte de la nada y de la ausencia de conciencia histórica del significado. El desheredarse de una trayectoria de sabiduría más grande que nos precede y se ofrece a la experiencia y a la razón, como recurso para una identificación consistente y para un pluralismo cultural razonable, se proyecta como rechazo de toda convicción que exceda las propias medidas dentro del presente individualista. Éste es en sí mismo inconexo y precario, incapaz de producir una concepción omnienglobante del bien, según el lenguaje de Rawls. Una identidad personal crítica se adquiere en un proceso no escéptico de problematización y de esclarecimiento. Éste se realiza en el reconocimiento del conjunto posible del propio pasado histórico, asido en su propuesta esencial como hipótesis global, sintética y coherente, a examinar y verificar. Sin una tal propuesta, la libertad no se arriesga con atención y con responsabilidad dentro de un compromiso racional con la verdad última correspondiente a la demanda alterativa del bien, que otorga un horizonte abierto y pre-

\footnotetext{
${ }^{25}$ Ricoeur P., ibidem, p. 305
} 
ciso de identificación y de satisfacción, sin suprimir la dramaticidad de la libertad frente a los irrevocables problemas humanos.

$\mathrm{Si}$ "el liberalismo político concibe esa diversidad de doctrinas razonables (hipótesis de sentido, tradiciones históricas) como el resultado inevitable a largo plazo de las facultades de la razón humana desarrolladas en el marco de instituciones duraderas libres" ${ }^{26}$, entonces, ese pluralismo democrático efectivo precisa, para continuarse, de un desarrollo fundamental del espacio público social de comunicación del sentido del pasado histórico, como clave del fortalecimiento de la alteridad meta-política plural de la sociedad civil, respecto a la necesaria instrumentalidad del estado unificador. "Tradición y memoria son fenómenos solidarios y con la misma estructura narrativa. Pero es preciso aprender, bajo presión de la crítica histórica, a desdoblar el fenómeno de la tradición, tal como aprendimos a desdoblar la memoria entre memoria-repetición y memoria-reconstrucción. La tradición tratada como depósito muerto tiene que ver con la misma compulsión repetitiva propia de la memoria traumática" ${ }^{27}$. Por el contrario, "la tradición, formalmente concebida como tradicionalidad, constituye un fenómeno de gran alcance. Significa que la distancia temporal que nos separa del pasado no es un intervalo muerto, sino una transmisión generadora de sentido. Antes de ser un depósito inerte, la tradición es una operación que sólo se comprende dialécticamente en el intercambio entre el pasado interpretado y el presente que interpreta" ${ }^{28}$.

El mismo Ricoeur ${ }^{29}$ ayuda a entender esto: la apropiación crítica de una tradición no comienza por la capacidad de construir un artificio epistemológico que la reduzca anecdóticamente o la derive hacia aspectos secundarios, sino que desarrolla la tensión interna a la experiencia misma del yo-encarnado, como lugar de

\footnotetext{
${ }^{26}$ Rawls J., Liberalismo político, p. 33

${ }^{27}$ Ricoeur, P.. "La marque du passé", Revue de Métaphysique et de Morale, n 1 (1998), p. 30

${ }^{28}$ Ricoeur P., Temps et Récit III. Le temps raconté. Paris, Seuil 1985, p. 320

${ }^{29}$ Cfr. Ricoeur P., ibidem, pp. 318-319
} 
recepción y de proyección de lo que ya lo constituye. Esta tensión se concentra en el presente, en el instante del yo, capaz de sintonizar receptivamente con lo grande y decisivo del legado histórico, en la medida en que él-mismo mantiene despierta la grandeza de su propio deseo-de-ser y de su preguntar. En la recepción se relanza lo recibido en expectativas determinadas que abren concretamente el futuro. La conciencia histórica se apropia de lo esencial. Entre eficiencia del pasado que padecemos (por el hecho de pertenecer a una historia que siempre nos hace suceder) y recepción del pasado, que realizamos (por el hecho de estar a distancia en el tiempo y respecto a sí-mismo), se ubica la tendencia a la des-memoria (olvido) y el consecuente empeño por re-conocer, heredar y ser beneficiarios del acontecimiento que establece el filum de la historicidad, abriendo una tradición. La distancia crítica de la conciencia histórica es, entonces, una distancia atravesada que supera tanto la lejanía ingenua del pasado "antiguo" superado, cuanto la contemporaneidad sentimental del pasado vuelto totalmente inmediato, sin pasar por la crisis y la apropiación. Sin embargo, un acontecimiento es verdaderamente tal si por sí mismo re-acontece en la actualidad de un signo real que despierta al yo-encarnado como autoconciencia. Pues el yo es, en su constitutiva irrepetibilidad y en su deseo ilimitable, una excepción en el mundo, transpasándolo. Pero sólo en cuanto investido por un acontecimiento personal, históricoontológico, que imprevistamente le corresponde en totalidad, se posibilita la autoconciencia del yo como tal, abriendo un itinerario generacional de novedad capaz de transformar al mundo, a través del sistema concreto de las relaciones. Instaurando en el mundo una historia.

La "tradicionalidad designa la dialéctica entre el distanciamiento y la des-distanciación" ${ }^{130}$, por donde se inserta la novedad. Dialéctica en la que se realiza la recepción del pasado en su "pretensión de verdad [el tener-por-verdadero, como hipótesis positiva,

\footnotetext{
${ }^{30}$ Ricoeur P., ibidem, p. 319
} 
que permite un auténtico trabajo innovador], ofrecida a la argumentación [a la verificación integral y no sólo a un proceso discursivo] en el espacio público de la discusión [y, sobre todo, de los auténticos encuentros humanos]. Frente a la crítica que se devora a sí misma, la pretensión de verdad de los contenidos de las tradiciones merece ser considerada como una presunción de verdad, hasta que se haga valer una razón más fuerte, es decir, un argumento mejor" ${ }^{\prime 31}$. Y no sólo eso, sino un nuevo signo objetivo o contenido encarnado y presente, portador de una experiencia totalizante y universalmente significativa, que pueda ser más correspondiente a la propia exigencia de ipseidad. La trascendentalidad fenomenológico-política del concepto de ciudadanía y de pluralidad cultural es evidentemente necesaria para dar lugar a esta dramática personal de la identificación y de la autoconciencia histórica que, a su vez, funda ontológicamente una democracia viva.

\section{Resumen}

Para Rawls, el problema de la filosofía política es la existencia duradera de una sociedad democrática, cuyos ciudadanos, sin embargo, no dejan de estar "profundamente divididos" por doctrinas religiosas, filosóficas y morales razonables. La convivencia de tal pluralidad en un espacio jurídico-estatal, está conformada por ideas intuitivas básicas, decantadas en un consenso superpuesto, que expresa la historicidad cultural de tal sociedad. Pero la trascendentalidad reflexiva del concepto ético-político de ciudadano debe realizar una epokhé sobre los procesos culturales de identificación que la posibilitan. La justicia constitucional como equidad establece la discriminante entre razón pública y razón privada. Pero para el A. la privatización de la racionalidad personal y cultural socava la durabilidad y estabilidad postuladas. Los procesos de identifica-

\footnotetext{
${ }^{31}$ Ricoeur P., ibidem, pp. 328-329
} 
ción personal y cultural consistentes, no se resuelven en la mera privacidad ni progresan en la mutua extraneidad de la tolerancia pasiva e indiferente, que concentra la vida pública en el sólo horizonte del poder. Ricoeur elabora el concepto de tolerancia dificil o virtuosa. Implica autoconciencia de la propia identidad y diálogo crítico en el espacio público de la pluralidad como libertad cultural y educativa. La hipótesis de significado transmitida por el propio pasado histórico es una instancia fundamental de confrontación para identificaciones exigentes. Éstas consolidan la intercomunicación en el espacio público de la sociedad civil, generando una democracia viva y durable.

\section{Abstract}

According to Rawls, the problem of the political philosophy is the lasting existence of a democratic society whose citizens, however, do not stop being "deeply divided" by reasonable religious, philosophical and moral doctrines. The act of living together in such plurality in a juridical state space is conformed by intuitive basic ideas, decanted in an overlapping consent, that expresses the cultural historicity of such society. But the reflexive transcendentalism of the ethical-political concept of citizen, must achieve an epoché of the cultural process of identification that will make it possible. The constitutional justice as equity sets down the discrimination between public reason and private reason. But for the $\mathrm{A}$. the privatization of the personal and cultural rationality undercuts the postulated durability and stability. The processes of consistent personal and cultural identifications cannot be solved in mere privacy and they do not progress in the mutual extraneity of the passive and indifferent tolerance that concentrates the public life only in power horizon. Ricoeur elaborates the concept of difficult or virtuous tolerance. It implicates self-consciousness of the proper identity and critical dialogue in the public space of the plurality, as cultural and educative freedom. The hypothesis of meaning transmitted by its own historical past is a fundamental instance of confrontation for 
exigent identifications. These consolidate the intercommunication in the public space of the civil society, generating a live and durable democracy. 